\title{
A new bomb-combustion system for tritium extraction
}

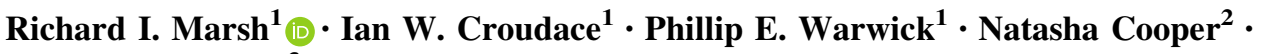 \\ Nadereh St-Amant ${ }^{3}$
}

Received: 29 June 2017 / Published online: 8 September 2017

(C) The Author(s) 2017. This article is an open access publication

\begin{abstract}
Quantitative extraction of tritium from a sample matrix is critical to efficient measurement of the low-energy pure beta emitter. Oxidative pyrolysis using a tube furnace (Pyrolyser) has been adopted as an industry standard approach for the liberation of tritium (Warwick et al. in Anal Chim Acta 676:93-102, 2010) however pyrolysis of organic-rich materials can be problematic. Practically, the mass of organic rich sample combusted is typically limited to $<1 \mathrm{~g}$ to minimise the possibility of incomplete combustion. This can have an impact on both the limit of detection that can be achieved and how representative the subsample is of the bulk material, particularly in the case of heterogeneous soft waste. Raddec International Ltd (Southampton, UK), in conjunction with GAU-Radioanalytical, has developed a new high-capacity oxygen combustion bomb (the Hyperbaric Oxidiser; $\mathrm{HBO}_{2}$ ) to address this challenge. The system is capable of quantitatively combusting samples of 20-30 g under an excess of oxygen, facilitating rapid extraction of total tritium from a wide range sample types.
\end{abstract}

Keywords Tritium - Tritium extraction - Organically bound tritium - Bomb-combustion - Waste characterisation

Richard I. Marsh

Richard.marsh@noc.soton.ac.uk

1 GAU-Radioanalytical Laboratories, OES, National Oceanography Centre Southampton, University of Southampton, Southampton SO14 3ZH, UK

2 Culham Centre for Fusion Energy, Abingdon OX14 3DB, UK

3 Canadian Nuclear Safety Commission, Ottawa ON K1P 5S9, Canada

\section{Introduction}

Tritium $\left({ }^{3} \mathrm{H}\right)$ is a low-energy pure beta emitter $\left(E_{\max }\right.$ $18.6 \mathrm{keV}$ ) produced as a by-product of nuclear power plant operations, employed as a potential fuel in fusion reactors and utilised as a radiolabel in life science research. Direct measurement of ${ }^{3} \mathrm{H}$ in solid and certain liquid samples is not possible as the weak beta emissions are rapidly attenuated by the sample matrix [1]. Liberation of ${ }^{3} \mathrm{H}$ from the host matrix is therefore a critical stage in the analytical process. Numerous techniques have been developed to facilitate ${ }^{3} \mathrm{H}$ extraction from a wide range of sample matrices including tube based combustion furnaces such as the Raddec Pyrolyser-6 trio [2, 3] and automated sample oxidisers such as the Perkin Elmer 307 and Zinsser Ox-501 [4]. Tube furnaces such as the Pyrolyser are highly flexible as they have been extensively tested, offer robust ${ }^{3} \mathrm{H}$ extraction from a wide range of sample matrices [5] and can accommodate up to six samples per extraction. The principal limitation of such systems is that their capacity for organic-rich sample types must be limited to $<1 \mathrm{~g}$ in order to minimise the possibility of pressure excursions and incomplete combustion [6]. Sample oxidisers are better suited to organic matrices but sample size is typically limited to between 0.5 and $1 \mathrm{~g}$ as such systems were originally developed for the analysis of radiolabelled biological material for which a high sample capacity was not required. Neither technique can be considered ideal for the analysis of organic-rich sample types and we can identify a number of scenarios where the ability to combust a much larger sample mass would be beneficial (Table 1).

An alternative technique that has been successfully applied to the extraction of ${ }^{3} \mathrm{H}$ from organic rich samples is oxygen-bomb combustion $[9,10]$. Using this procedure, the sample is contained within a pressure vessel containing 
Table 1 Analytical scenario where an approach capable of processing large, organic-rich samples matrices may be beneficial

\begin{tabular}{ll}
\hline $\begin{array}{l}\text { E } \mathrm{H} \text { analysis scenario } \\
\text { monitoning }\end{array}$ & $\begin{array}{c}\text { Analytical requirements/challenges } \\
\text { Analysis of biota to assess potential food-chain transfer and dose to critical groups. Typically large sample sizes must be } \\
\text { prepared in order to meet demanding limits of detection (LODs). This is particularly applicable to the assessment of } \\
\text { organically bound tritium }(\mathrm{OBT})[7,8]\end{array}$ \\
$\begin{array}{c}\text { Nuclear } \\
\text { Recommissioning } \\
\text { difficult to process by other extraction techniques }\end{array}$ \\
$\begin{array}{c}\text { Fusion reactor } \\
\text { operations }\end{array}$ & $\begin{array}{c}\text { Analysis of }{ }^{3} \mathrm{H} \text { contaminated soft wastes (e.g. gloves, coveralls, plastic sheeting, paper towel). Contamination may be } \\
\text { heterogeneously distributed due to composition and large samples are required to ensure representative analysis }\end{array}$ \\
\hline
\end{tabular}

a significant excess of oxygen. Ignition results in rapid oxidation of the sample and the conversion of all hydrogen (and hence also ${ }^{3} \mathrm{H}$ ) present to $\mathrm{H}_{2} \mathrm{O}$, which can subsequently be recovered for ${ }^{3} \mathrm{H}$ analysis. The application of this approach has remained relatively limited however due to the lack of availability of commercial systems. Only the Parr model 1121 employed by Moghissi et al. [10] is readily available and sample mass is limited to a maximum of $10 \mathrm{~g}$. Furthermore this system requires implementation of suitable ancillary equipment to enable the quantitative recovery of the resulting combustion water.

This paper outlines the evaluation of a recently developed oxygen-combustion bomb designed specifically to address these analytical requirements, the Raddec Hyperbaric Oxidiser, $\mathrm{HBO}_{2}[1,11]$. A summary of pre-production testing and two application case studies from current users of the system are described; environmental monitoring (Canadian Nuclear Safety Commission, Ottawa, Canada) and fusion reactor operational support (JET, Joint European Torus, CCFE, Didcot, UK).

\section{Materials and methods}

\section{The hyperbaric oxidiser $\left(\mathrm{HBO}_{2}\right)$}

The $\mathrm{HBO}_{2}$ (Raddec International Ltd, Southampton, UK) comprises of a 5 litre high-strength pressure vessel machined from 316 grade stainless steel. A recent enhancement plans to use a more chemically-resistant Hastelloy ${ }^{\mathrm{TM}}$ that is more tolerant to $\mathrm{HCl}$ and nitric acid generated during oxidative decomposition. The vessel is supported within a stainless steel frame that also houses the combustion product recovery pipework, power $(24 \mathrm{~V})$ and monitoring systems (Fig. 1). The pressure vessel incorporates a resistance wire ignition system along with gas pressure and gas temperature sensors (K-type thermocouple) and a pressure-vessel temperature sensor. Samples are loaded into the vessel through a double-hinged door, which incorporates a borosilicate glass viewing window
(Visilume, Glossop, UK) and tapered-lug door locking mechanism. The door closure mechanism incorporates dual safety interlocks to prevent ignition should the door not be properly secured prior to combustion. A removable stainless steel liner is installed to reduce wear and prolong pressure vessel life. Oxygen is introduced via gas inlet line governed by two independent valves located on the front panel (one needle type for fine metering, one ball for coarse control) and a check valve is installed to prevent backflow from the vessel. Exhaust gases leave the chamber via a $25 \mu \mathrm{m}$ mesh stainless steel pre-filter and a $7 \mu \mathrm{m}$ secondary, sintered filter (both removable for cleaning). Exhaust release is controlled via a needle valve on the front panel (valve 'D'; Fig. 1) and can be diverted to a dual-borosilicate cryo-trap electrically-cooled to $-110{ }^{\circ} \mathrm{C}$ via flexible PFA tubing for initial combustion water recovery or to a dry-scroll vacuum pump for recovery of residual water once ambient pressure is reached in the vessel. Exhaust gas flow is controlled by a single stage regulator and thermal mass flow controller (TMFC) (Fig. 2).

Vessel gas pressure, temperature and vessel body temperature data are measured during operation and output to digital displays on the front panel and by USB ('2' on rear panel detail; Fig. 1) to a computer via a NI DAQ and LabVIEW interface (National Instruments, Texas, USA). Regulator gas pressure and flow rate are also displayed. The combustion process is illustrated in Fig. 2. Solid samples may be combusted directly as can viscous liquids (e.g. oils). Powdered samples must be compressed into a pellet prior to combustion to prevent formation of an aerosol during filling/combustion that could result in an uncontrolled combustion. Typically a $40 \mathrm{~mm}$ diameter XRF press such as the HTP 40 (Herzog, Osnabruck, Germany) is used for pelleting, capable of compressing powdered samples to $200 \mathrm{kN}$.

\section{Pre-production evaluation}

Initial evaluation of the system was completed through non-active testing and active commissioning. Non-active 


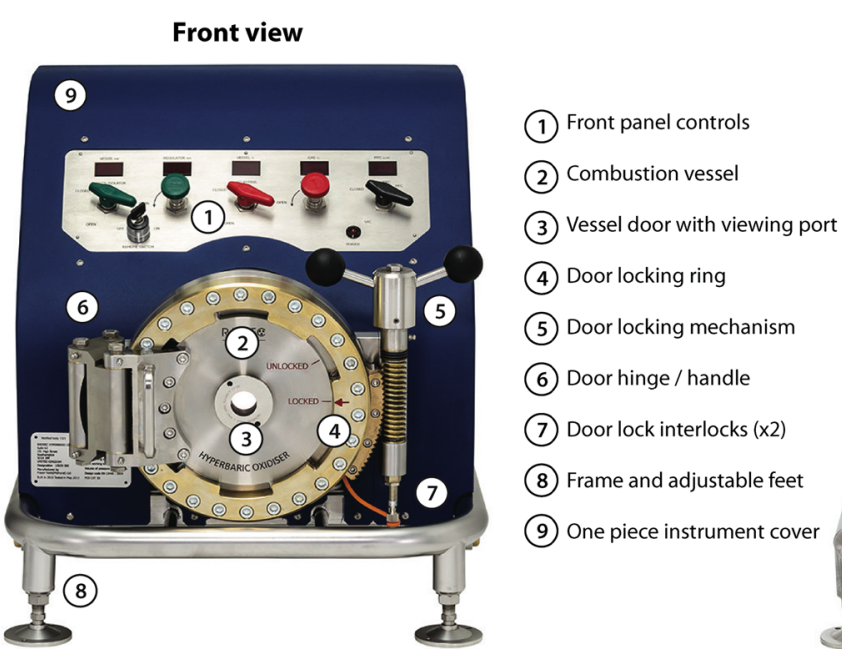

Front panel (detail)

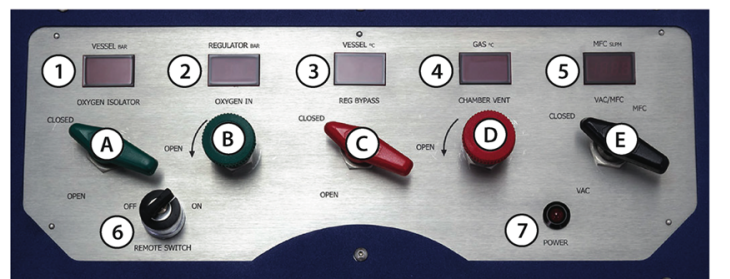

LED Displays Switches / Indicators Valves

(1) Vessel pressure (6) Remote firing (A) Oxygen inlet (ball valve)

(2) Regulator pressure (7) Power indicator (B) Oxygen inlet (needle valve)

$\begin{array}{ll}\text { (3) Vessel temperature } & \text { (C) Regulator bypass } \\ \left({ }^{\circ} \mathrm{C}\right) & \end{array}$

(4) Gas temperature (D) Chamber vent (needle valve)

(5) MFC flow (SLPM)

(E) MFC/Vacuum selector

Fig. 1 Key components of the $\mathrm{HBO}_{2}$

testing comprised of the combustion of cellulose $\left(\left(\mathrm{C}_{6} \mathrm{H}_{10} \mathrm{O}_{5}\right)_{\mathrm{n}}\right)$ pellets of varying masses $(5-25 \mathrm{~g})$ and stoichiometric calculation of the theoretical combustion water yield. This was compared to the actual combustion water yield determined gravimetrically to infer recovery. Assessment of optimum vacuum recovery time and variation with sample mass was also completed by combustion of known quantities of cellulose. For active testing, $10 \mathrm{~g}$ cellulose pellets were spiked with a known activity of tritiated water (Amersham Bioscience, UK) and combusted. Aliquots of the combustion water were mixed with scintillation cocktail (Goldstar, Meridian Biotechnologies, UK) in $20 \mathrm{ml}$ polyethylene vials (Meridian Biotechnologies, UK) and counted on a 1220 Quantulus Liquid scintillation Counter (LSC) (Wallac/Perkin Elmer, USA) to determine activity recovery. Samples of an organically bound ${ }^{3} \mathrm{H}$ (OBT) reference material ${ }^{3} \mathrm{H}$-thymidine doped milk powder) were also pelletised with cellulose and combusted and the combustion water analysed in the same way.
Rear view (cover removed)

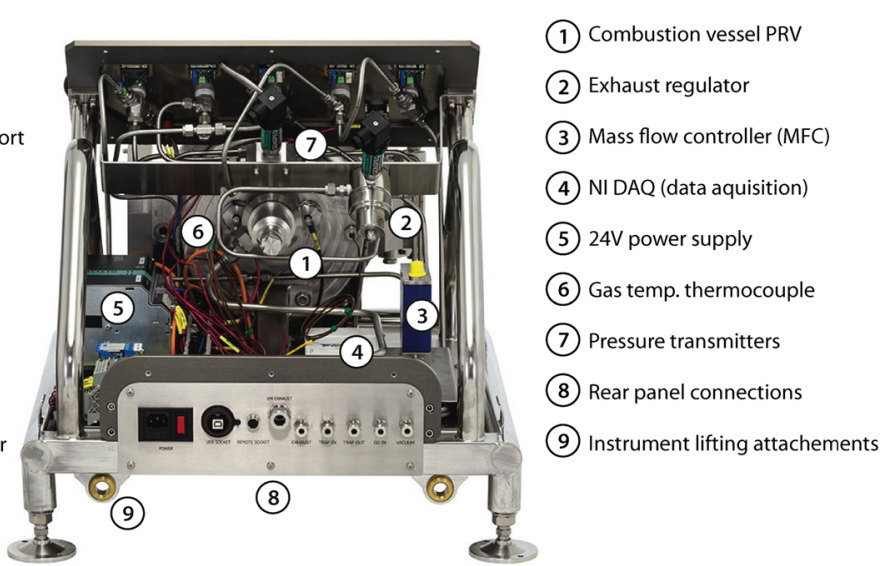

Rear panel (detail)

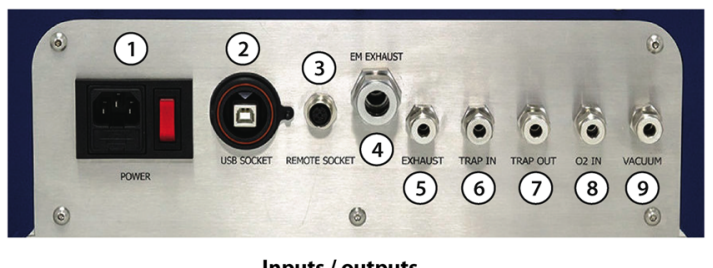
(1) $240 \mathrm{~V}$ power inlet /
(6) Cryo-trap inlet (trap » $\mathrm{HBO}_{2}$ )
(2) USB outlet
(7) Cryo-trap outlet $\left(\mathrm{HBO}_{2}\right.$ ) trap)
(3) Firing remote inlet
(8) Oxygen inlet
(4) Emergency exhaust outlet
(9) Vacuum inlet (Vac.» $\mathrm{HBO}_{2}$ )
(5) Exhaust outlet

\section{Environmental ${ }^{3} \mathrm{H}$ analysis}

Analysis of environmental samples was completed by Canadian Nuclear Safety Commission (CNSC), Ottawa, as part of routine regulatory surveillance in the vicinity of nuclear facilities known to handle ${ }^{3} \mathrm{H}$. Biota samples including fruit/berries, vegetables (beetroot, potatoes and carrot), milk and meat (beef, chicken and fish) were analysed for OBT content. All samples were dehydrated by freeze-drying and homogenised using a cutting/grinding mill (MF10, IKA, Germany). Approximately $10 \mathrm{~g}$ of each sample type was pelletised using a hydraulic press. Samples were combusted in the $\mathrm{HBO}_{2}$ under 20 bar of oxygen and the combustion water analysed directly or following distillation. Pelletised samples were also combusted using a Parr 1121 combustion bomb for comparison. Water was collected directly from the vessel and distilled prior to analysis. For all samples the combustion water was mixed with Ultima Gold LLT scintillation cocktail (Perkin Elmer, USA) and counted on a Tricarb TR3180 (Perkin Elmer, 


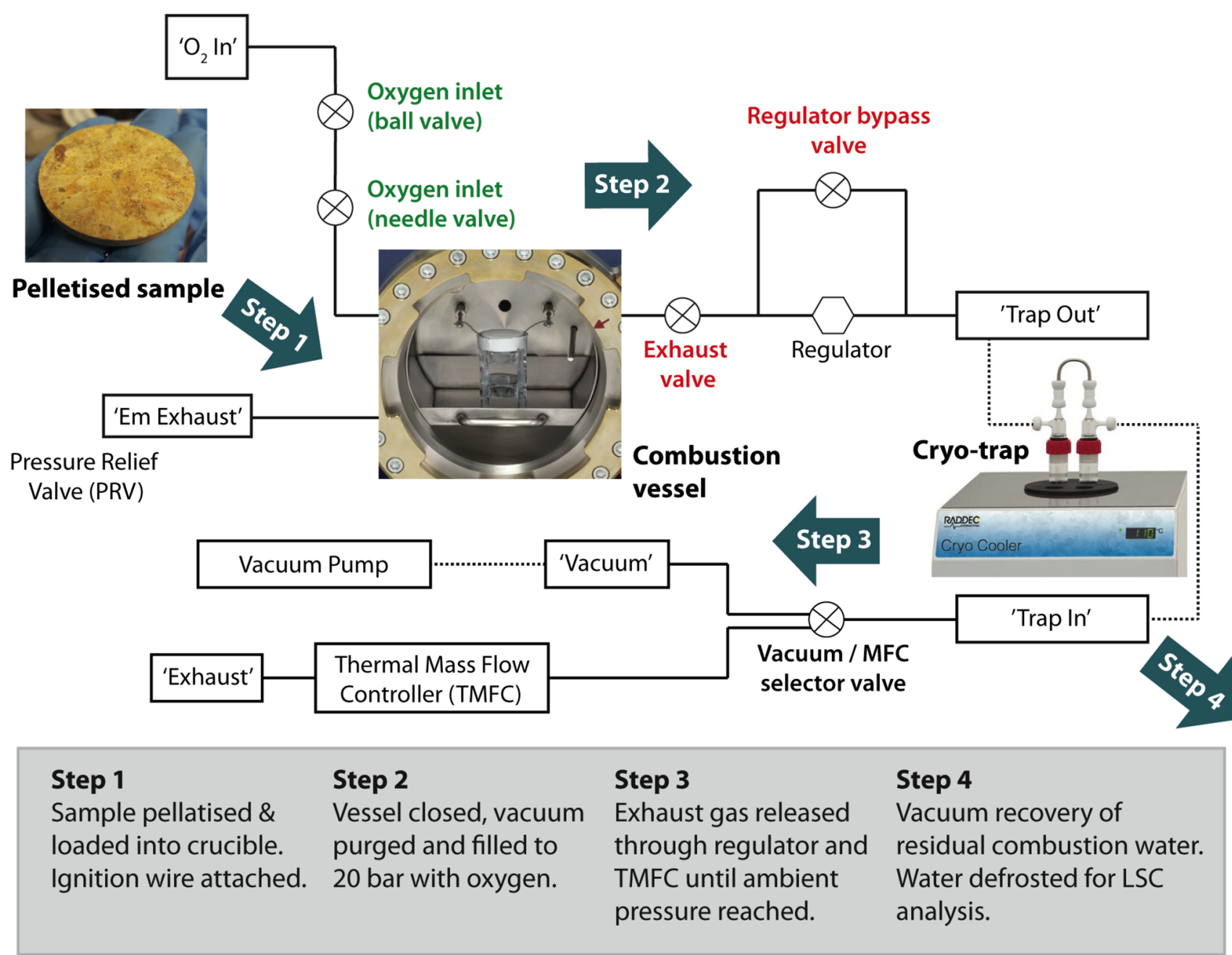

Fig. $2 \mathrm{HBO}_{2}$ flow schematic and combustion procedure

USA). Sample quench was evaluated using the tSIE parameter and corrected based on 'in-house' quench curves prepared using matrix-matched standards quenched with nitromethane.

\section{JET fusion reactor soft waste characterisation}

Analysis of fusion reactor soft wastes was completed by Culham Centre for Fusion Energy (Didcot, UK) as part of their operational waste characterisation program. Samples of polyvinylchloride (PVC), fibreboard and 'housekeeping waste' (a heterogeneous mixture of nitrile gloves, cellulose paper/tissues, various plastics and cotton) were divided by hand (cutting) and pelletised using a hydraulic press. Microcrystaline cellulose powder (Sigma Aldrich, UK) was added to housekeeping samples as a binding agent and the effect of shrink wrapping pellets in non-PVC film prior to combustion was also investigated. Tritium memory effect of the $\mathrm{HBO}_{2}$ was assessed through subsequent combustion of blank cellulose pellets immediately following sample combustion and comparison of the total activity recovered with that of the sample. The combustion of blank cellulose pellets was also used to reduce the system memory between sample combustions. Subsamples of the combustion water $(4 \mathrm{ml})$ were mixed with $16 \mathrm{ml}$ of Ultima Gold scintillation cocktail (Perkin Elmer, USA) and counted on a Tricarb TR2810 (Perkin Elmer, USA). Constant quench was assumed provided that the tSIE parameter fell within a defined acceptable range. Subsamples of each sample type were also processed using a Pyrolyser-6 trio furnace (Raddec International, Southampton, UK) for comparison purposes. Samples were combusted using a 4-hour protocol under air and oxygen to a maximum temperature of $800{ }^{\circ} \mathrm{C}$. 


\section{Results}

\section{Pre-production evaluation}

Complete recovery of combustion water resulting from $10 \mathrm{~g}$ cellulose pellets was achieved with vacuum pumping time of $10 \mathrm{~min}$ (based on a theoretical yield of $0.61 \mathrm{~g}$ of combustion water per gram of cellulose). The majority of combustion water was recovered in the first tube of the cryo-trap (91-95\%) with minimal carry over to the second trap. Depending on the temperature of the combustion vessel a further $10 \mathrm{~min}$ per $10 \mathrm{~g}$ increase in sample mass was generally found to be sufficient for optimum combustion water recovery. The mass of combustion water recovered following the combustion of cellulose pellets from 5 to $25 \mathrm{~g}$ in mass showed close agreement with the theoretical mass (Fig. 3). For each test the distribution of liquid between the two cold traps remained constant within uncertainty (5-9\% carried over to the second trap). A mean HTO recovery of $101 \pm 3 \%(k=2, n=10)$ was determined with a mean counting efficiency of $23 \%$. A mean OBT recovery of $97 \pm 13 \%$ was achieved $(k=2, n=8$; Fig. 4) with a mean counting efficiency of $12 \%$.

\section{Environmental ${ }^{3} \mathrm{H}$ analysis}

Successful combustion of all sample matrices was achieved in the $\mathrm{HBO}_{2}$, with minimal combustion residue and complete recovery of combustion water. The OBT activity measured in the biota samples ranged from 1.5 to $56 \mathrm{~Bq} / \mathrm{kg}$ for both the Parr and $\mathrm{HBO}_{2}$ (in cases where samples were analysed by both systems results were below the LOD). Combustion of cellulose pellets between biota samples indicated no significant between-sample memory (results were LOD). Combustion water recovered from the $\mathrm{HBO}_{2}$

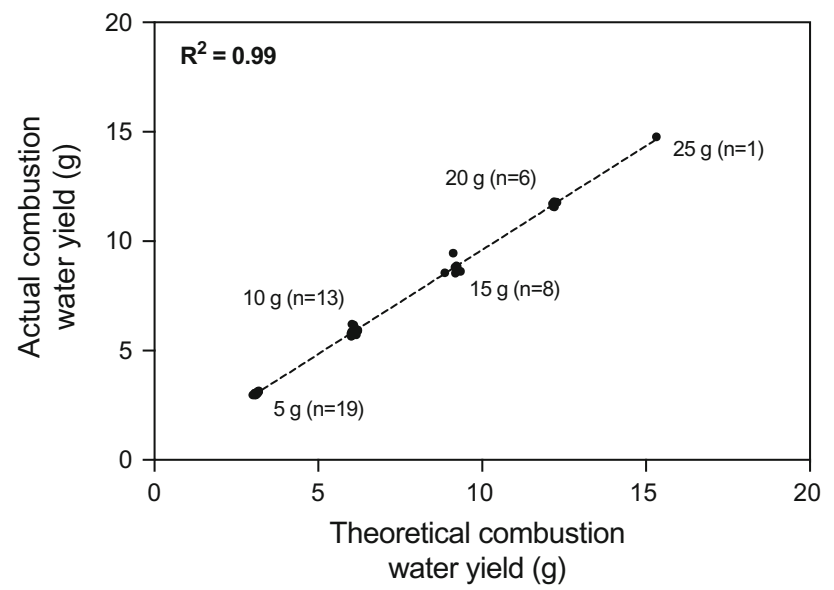

Fig. 3 Actual versus theoretical combustion water yield for various masses of cellulose combusted using the $\mathrm{HBO}_{2}$

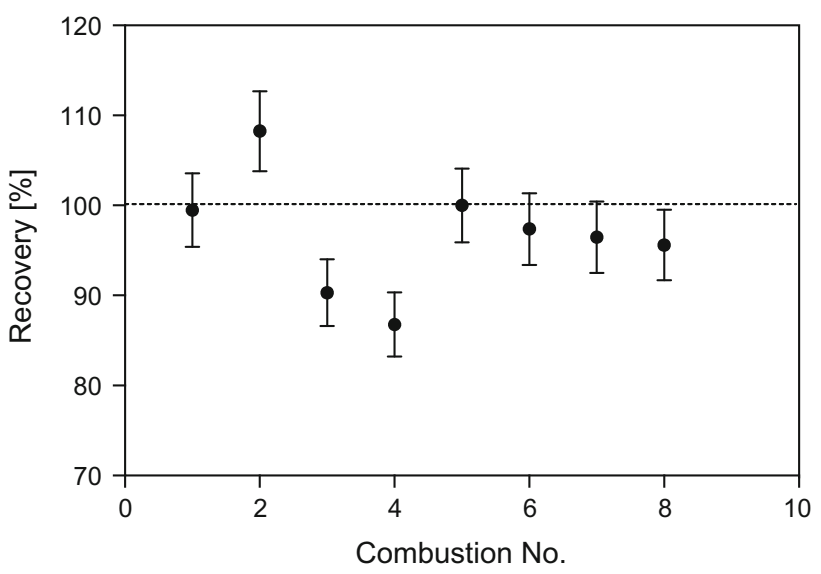

Fig. 4 Activity based recovery for eight OBT combustions in the $\mathrm{HBO}_{2}\left({ }^{3} \mathrm{H}\right.$-thymidine doped milk powder; reference activity of $3.4 \pm 1.2 \mathrm{~Bq} / \mathrm{g}$ )

was noticeably clearer than water recovered directly from the Parr (Fig. 5). The LOD and counting efficiency for a typical sample are shown in Table 2 and a relative reduction in counting efficiency of up to $25 \%$ is apparent for combustion water from the Parr compared to that from the $\mathrm{HBO}_{2}$.

\section{${ }^{3} \mathrm{H}$ analysis in fusion reactor soft wastes}

Fibreboard and PVC samples were combusted with minimal combustion residue and complete combustion water recovery. Combustion of 'housekeeping' samples initially resulted in elevated levels of combustion residue deposited inside the vessel liner, rear face and door. Incomplete combustion was reduced considerably by forming the pellet inside non-PVC wrapping film (Fig. 6). Activity data for samples of fibreboard, PVC and 'housekeeping' prepared using the $\mathrm{HBO}_{2}$ were comparable to measurements performed on sample prepared using the Pyrolyser furnace

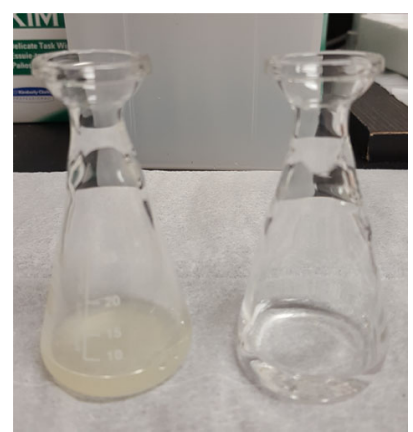

Fig. 5 Comparison of combustion water obtained using the Parr 1121 (left) and $\mathrm{HBO}_{2}$ (right) 
Table 2 LOD and counting efficiency data for the $\mathrm{HBO}_{2}$ and Parr 1121

\begin{tabular}{lll}
\hline Parameter & Hyperbaric oxidiser $\left(\mathrm{HBO}_{2}\right)$ & Parr 1211 high capacity (1.85 L) bomb \\
\hline Typical LOD (10 g sample) & $2 \mathrm{~Bq} / \mathrm{kg}$ & $3 \mathrm{~Bq} / \mathrm{kg}$ \\
Lower LOD (20-30 g sample) & $1 \mathrm{~Bq} / \mathrm{kg}(20 \mathrm{ml}$ vial; potentially lower with $100 \mathrm{ml}$ vial $)$ & - \\
tSIE difference (ref. distilled water) & $0-1 \%$ & $12-24 \%$ \\
\hline
\end{tabular}
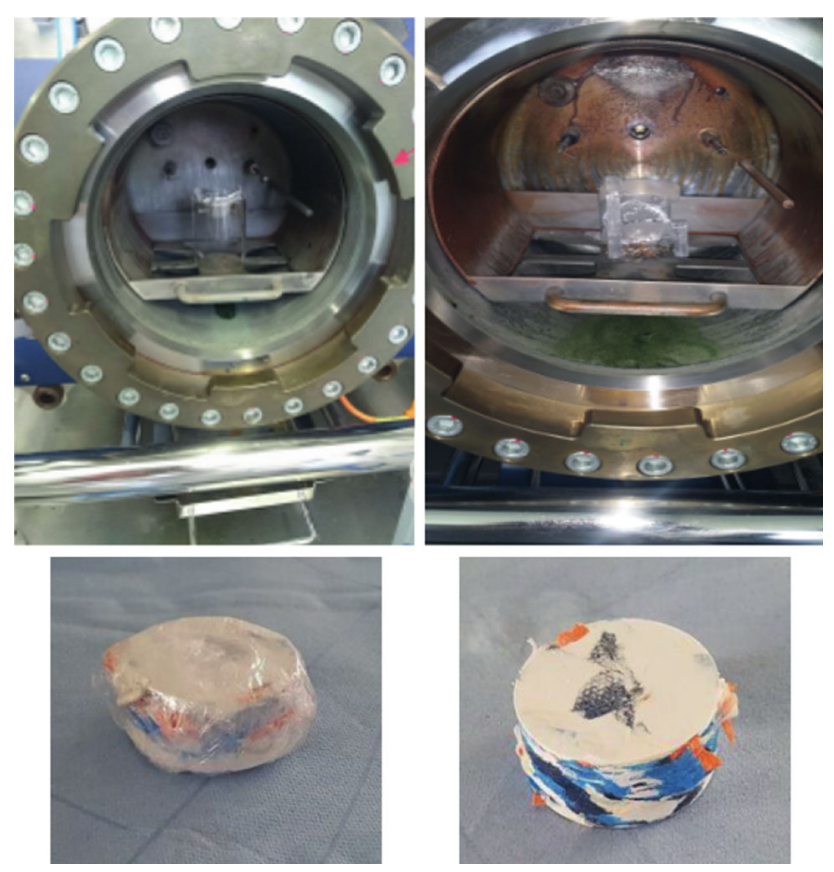

Fig. 6 Comparison of residues after combustion of a mixed waste 'housekeeping' pellet with non-PVC film wrap (left) and without film wrap (right)

with the exception of the 'housekeeping' samples (Table 3 ). The ${ }^{3} \mathrm{H}$ background or 'memory effect' following active sample combustion ranged from 0.3 to $1.3 \%$ (Table 3) for activity inventories of up to approximately $100 \mathrm{kBq}$.

\section{Discussion}

Pre-production evaluation of the performance of the $\mathrm{HBO}_{2}$ indicates that the system is capable of quantitatively combusting samples of $25 \mathrm{~g}$. The upper limit for sample mass is dependent on sample type and maximum combustion pressure reached; for most matrices combustion of $30 \mathrm{~g}$ should be achievable. The combination of cryo-trapping, vacuum evacuation and an integrated gas handling system enables efficient combustion water recovery and hence tritium recoveries $>95 \%$ for HTO and OBT. The former is indicative of efficient combustion water trapping where as the later validates both quantitative extraction and trapping. The variability associated with the OBT recovery is considered acceptable $( \pm 13 \%, k=2)$ based on uncertainty of the standard reference value ${ }^{1}(34 \%, k=2$, $n=10)$. The significant difference in counting efficiencies observed between HTO and OBT samples is thought to be the result of acid formation during combustion of the milk matrix, which results in an increase in chemical quench during counting. By comparison, combustion of the cellulose matrix used for the HTO samples does not result in significant acid production (trace amounts of acid may be produced as a result of impurities in the cellulose and residual gasses present in the chamber from laboratory air). The author has used the addition of $\mathrm{Na}_{2} \mathrm{CO}_{3}$ to neutralise acids present in the combustion water and significantly improve counting efficiencies for organic rich samples (22-26\% for marine biota samples [1]). Quantitative activity recovery is corroborated by a $1: 1$ ratio of theoretical versus actual combustion water yields for cellulose pellet combustions. Furthermore, assessment of vacuum pumping duration indicates that complete recovery can be achieved between 20 and $30 \mathrm{~min}$ for a $20 \mathrm{~g}$ sample depending on the vessel body temperature; enhanced evaporation occurs if successive combustions are completed over a short period [1].

A range of biota samples have been successfully combusted in the $\mathrm{HBO}_{2}$ and in all cases combustion residues were reduced when compared to similar combustions in the Parr system. This reduction is facilitated by the use of a special low-thermal mass crucible and quartz glass support, which minimises quench during combustion compared to a conventional metallic crucible. The vacuum recovery of combustion water combined with reduced combustion residue result in cleaner combustion water, which is less prone to colour and chemical quenching during LSC. It is also possible to recover a larger volume of combustion water for a comparable sample mass using the $\mathrm{HBO}_{2}$, resulting in an improvement in the LOD. Further LOD improvements are possible by maximizing sample mass when compared to other combustion bomb systems (up to

\footnotetext{
${ }^{1}$ Determined through replicate combustions of the standard using a Pyrolyser furnace as part of the characterisation process during standard preparation.
} 
Table 3 Fusion reactor soft waste activity data obtained using the $\mathrm{HBO}_{2}$ and Pyrolyser systems

\begin{tabular}{lccl}
\hline Sample type & Hyperbaric oxidiser $[\mathrm{Bq} / \mathrm{g}]$ & Pyrolyser $[\mathrm{Bq} / \mathrm{g}]$ & $\mathrm{HBO}_{2}$ memory $[\%]$ \\
\hline Fibreboard 1 & $11,300 \pm 2000$ & $11,000 \pm 2000$ & 0.62 \\
Fibreboard 2 & $5900 \pm 1000$ & $8000 \pm 2000$ & 0.51 \\
'Housekeeping' 1 & $600 \pm 100$ & $3100 \pm 600$ & 0.33 \\
'Housekeeping' 2 & $80 \pm 20$ & $2700 \pm 500$ & 1.3 \\
PVC & $3000 \pm 600$ & $2600 \pm 500$ & Not measured \\
\hline
\end{tabular}

The ${ }^{3} \mathrm{H}$ 'memory effect' of the $\mathrm{HBO}_{2}$ system is also shown, measured in $\%$ of activity carried over from the active sample to a cellulose 'blank' combustion completed immediately afterwards

Table 4 Operational comparison of $\mathrm{HBO}_{2}$ and Parr 1121 system for OBT extraction

\begin{tabular}{ll}
\hline Hyperbaric Oxidiser $\left(\mathrm{HBO}_{2}\right)$ & Parr 1211 high capacity bomb \\
\hline $\begin{array}{l}\text { Maximum sample size of } 25+\mathrm{g} \\
\text { Sample combustion is visible via integrated viewing port }\end{array}$ & $\begin{array}{l}\text { Maximum sample mass limited to } 10 \mathrm{~g} \\
\text { No viewing port for combustion monitoring }\end{array}$ \\
$\begin{array}{l}\text { Provision of vacuum assisted combustion water recovery in easy to use } \\
\text { cryo-traps. }\end{array}$ & $\begin{array}{c}\text { Manual recovery of combustion water (complete recovery } \\
\text { difficult) } \\
\text { Clear combustion water which can be analysed directly by LSC }\end{array}$ \\
$\begin{array}{c}\text { Coloured combustion water which requires purification prior to } \\
\text { analysis }\end{array}$ \\
$\begin{array}{l}\text { Combustion time } \sim 2 \mathrm{~h} \text { per sample } \\
\text { Large system foot-print }\end{array}$ & $\begin{array}{l}\text { Compact system foot-print } \\
\text { High initial system cost }\end{array}$ \\
\hline
\end{tabular}

the maximum volume of combustion water which can be counted per analysis - typically $8-10 \mathrm{ml}$ for a $20 \mathrm{ml}$ vial or potentially $>15 \mathrm{ml}$ for a $100 \mathrm{ml}$ system). The most significant compromises when using the $\mathrm{HBO}_{2}$ are a slight increase in combustion time per sample and higher overall cost when compared to the Parr system. Comparison of operational experience with the $\mathrm{HBO}_{2}$ and Parr 1121 is given in Table 4.

The combustion of the diverse mixture of materials present in soft-waste streams generated by fusion reactor operations presents a significant challenge; oxidation of materials such as PVC and other plastics result in the production of strong acids and complex residues. Residues can be reduced by combining the sample with cellulose when pelleting and by wrapping the pellet in PVC-free wrapping film, which improves combustion efficiency and reduces combustion quench (note that the total activity recovered is not affected by the addition of cellulose hence no correction of the activity concentration is required when calculated back to the activity concentration of original sample). Damage to the combustion chamber is limited by the stainless steel liner and the removable internal filter limits ingress of combustion residue. Periodic cleaning of the gas handling system is achieved by flushing with a warm wash solution followed by distilled water rinse. Data for the waste materials tested show good agreement with that obtained by an established technique (Pyrolyser system) with the exception of the 'housekeeping' samples. The disparity between the data for this sample type is thought to be a result of the highly heterogeneous nature of this mixture and the associated sampling uncertainty. The $\mathrm{HBO}_{2}$ allows larger organic-rich samples to be processed in approximately $2 \mathrm{~h}$ per sample whereas a typical run on the Pyrolyser system has a duration of 4-6h. Up to 6 samples may be combusted per run using the Pyrolyser however the mass of organic rich sample processed is typically $0.5-1 \mathrm{~g}$ (maximum 4-5 g) compared to the 10-30 g for the $\mathrm{HBO}_{2}$. When combusting organic-rich samples, particularly when approaching the maximum capacity, tube furnace systems such as the Pyrolyser are also prone to additional complications such as pressure excursions and increased combustion residues, which can impact tritium recovery.

In summary the $\mathrm{HBO}_{2}$ enables rapid and efficient recovery of tritium from a diverse range of organic rich sample matrices that can be problematic for other extraction approaches. The system is particularly applicable to the combustion of biota where low LODs are required for environmental monitoring or for the preparation of organic-rich materials originating from nuclear decommissioning or facilities with significant ${ }^{3} \mathrm{H}$ inventories.

Acknowledgements The author would like to thank both the Culham Centre for Fusion Energy and the Canadian Nuclear Safety 
Commission for agreeing to share data and operational experiences with the $\mathrm{HBO}_{2}$.

Open Access This article is distributed under the terms of the Creative Commons Attribution 4.0 International License (http://crea tivecommons.org/licenses/by/4.0/), which permits unrestricted use, distribution, and reproduction in any medium, provided you give appropriate credit to the original author(s) and the source, provide a link to the Creative Commons license, and indicate if changes were made.

\section{References}

1. Marsh R (2010) Development of rapid and novel techniques for tritium extraction and analysis. $\mathrm{PhD}$ thesis

2. Warwick PE, Kim D, Croudace IW, Oh J (2010) Effective desorption of tritium from diverse solid matrices and its application to routine analysis of decommissioning materials. Anal Chim Acta 676:93-102

3. Kim DJ, Warwick PE, Croudace IW (2008) Tritium speciation in nuclear reactor bioshield concrete and its impact on accurate analysis. Anal Chem 80:5476-5480

4. Hou X (2005) Rapid analysis of ${ }^{14} \mathrm{C}$ and ${ }^{3} \mathrm{H}$ in graphite and concrete for decommissioining of a nuclear reactor. Appl Radiat Isot 62:871-882
5. Croudace IW, Warwick PE, Marsh R (2017) A suite of robust radioanalytical techniques for the determination of tritium and other volatile radionuclides in decommissioning wastes and environmental matrices. Fusion Sci Technol 71:290-295

6. Pointurier F, Baglan N, Alanic G, Chiappini R (2003) Determination of organically bound tritium background level in biological samples from a wide area in the South-West of France. J Environ Radioact 68:171-189

7. Baglan N, Kim SB, Cossonnet C, Croudace IW, Fournier M, Galeriu D, Warwick PE, Momoshima N, Ansoborlo E (2015) organically bound tritium analysis in environmental samples. Fusion Sci Technol 67:250-253

8. Baglan N, Kim SB, Cossonnet C, Croudace IW, Fournier M, Galeriu D, Warwick PE, Momoshima N, Ansoborlo E (2013) Organically bound tritium (OBT) behaviour and analysis: outcomes of the seminar held in Balaruc-les-Bains in May 2012. Radioprotection 48:127-144

9. Payne P, Done J (1954) Assay of tritium labelled substances: a combustion bomb method of preparation of gas for counting. Nature 174:27-28

10. Moghissi A, Bretthauer E, Whittaker E, McNelis D (1975) Oxygen bomb combustion of environmental and biological samples for tritium analysis. Int J Appl Radiat Isot 26:339-342

11. Croudace IW, Warwick PE, Marsh R (2011) Advances in tritium extraction methods to aid efficient waste characterisation. Nucl Future 7:48-53 